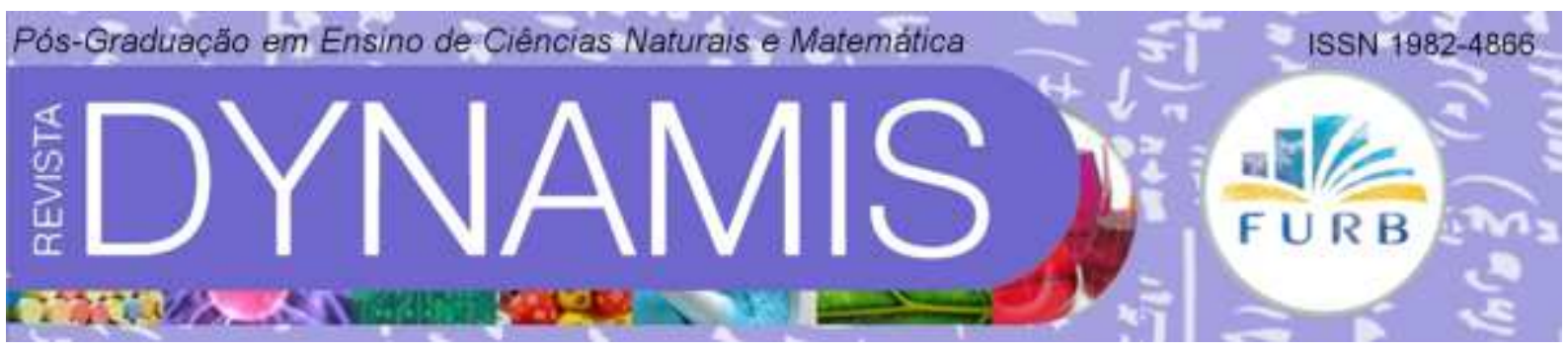

\title{
ECOFORMAÇÃO E TRANSDISCIPLINARIDADE NA REDE DE ESCOLAS CRIATIVAS ${ }^{1}$
}

Ecoformation and transdisciplinarity in the creative schools network

Saturnino de La Torre

Universidad de Barcelona-UB

sentipensar@yahoo.com

Vera Lúcia de Souza e Silva

Universidade Regional de Blumenau - FURB - PPGECIM

verass@terra.com.br

${ }^{1}$ Parte deste artigo foi publicado na obra Educação, Inovação e Resiliência (SUANO et al, 2013), e baseado em conteúdos da pesquisa intitulada Institutional Program Creative Schools Network and Teacher Training apresentada no Collóque International en Éducation, na Universidade de Montreal (Canadá/ maio/2013). 


\title{
Resumo
}

A transformação da prática educativa em convergência com as necessidades de sustentabilidade planetária e o estímulo a relações de convivência solidária e criativa são aspectos fundamentais em projetos de instituições educativas preocupadas em qualificar a vida no planeta. Nesta perspectiva baseia-se o Programa Institucional Rede de Escolas Criativas-RIEC, que objetiva auxiliar profissionais da educação em busca de práticas educativas que contemplem a ecoformação e a transdisciplinaridade. A experiência apresentada neste trabalho, concebida como uma possibilidade de ação em rede para promoção de ensino, pesquisa e extensão é reflexo de implementações de propósitos realizados pelos membros da RIEC.

Palavras chave: Ecoformação. Transdisciplinaridade. Rede de Escolas Criativas.

\begin{abstract}
The transformation of educational practice in convergence with the needs of planetary sustainability and stimulating relationships of solidarity and creative coexistence are fundamental aspects in projects concerned with life on the planet. In this perspective is based the Institutional Program Creative Schools Network -RIEC, which aims to help education professionals seeking educational practices that address the eco-formation and transdisciplinarity. The experience presented in this work, conceived as an opportunity to network action to promote teaching, research and extension reflects implementations of purpose made by members of RIEC.
\end{abstract}

Keywords: Ecoformation. Transdisciplinarity. Creative Schools Network. 


\section{INTRODUÇÃO}

Educar para a criatividade requer uma reforma paradigmática nos processos de construção e reorganização do conhecimento, uma reforma de pensamento (MORIN, 2000) e uma profunda transformação na educação (D'AMBROSIO, 2002; MARIOTTI, 2000; MORAES; TORRE, 2004; MORAES, 2008; SILVA, 2004 E 2013; TORRE, 2008, 2009, 2011). A transformação na direção de um sistema educacional que vise uma cultura de paz, que possa contribuir para mudanças significativas nas estruturas sociais, econômicas e culturais se apresenta como um desafio no século XXI, e a ecoformação e a transdisciplinaridade podem se apresentar como possibilidades para este processo de mudança.

Neste sentido, a transdisciplinaridade se coloca como referência para um trabalho que busca o diálogo dos saberes, de forma a contemplar temas atuais na comunidade escolar. Apresenta-se, assim, uma abordagem que reconhece a importância de se abrir para a individualidade de cada estudante, de cada cidadão. A transdisciplinaridade pode colaborar com novos princípios para ressignificar práticas educativas na direção da contextualização dos conteúdos, da complementaridade e articulação de saberes das diversas áreas do conhecimento para a superação da fragmentação. Isto para fortalecer a busca de uma escola humanizadora, criativa e centrada em processos que visem o bem-estar das pessoas, da sociedade e da natureza.

A transformação da prática educativa em convergência com as necessidades de sustentabilidade planetária e o estímulo a relações de convivência solidária e criativa são aspectos fundamentais em projetos de instituições educativas preocupadas em qualificar a vida no planeta. A sociedade vem sofrendo mudanças em muitos aspectos, entre eles a transformação da sociedade industrial para a sociedade da informação. Isto traz um progresso que exige saber lidar com o imprevisível e estar em busca contínua de novas soluções, o que exige enfrentar os problemas de forma inovadora e criativa. Neste contexto, a escola tem um papel fundamental na formação de cidadãos criativos, resilientes e empreendedores, que possam identificar problemas da realidade e solucioná-los por meio do que é estudado na escola. A finalidade das Escolas Criativas (Torre, 2009) é a de contribuir para uma educação atenta às necessidades presentes do século XXI, estimulando o desenvolvimento da consciência, de valores e da criatividade.

Nesta perspectiva baseia-se o Programa Institucional Rede de Escolas Criativas-RIEC FURB (www.escuelascreativas.com), que contempla os projetos: Formação Continuada para a criatividade e Escolas Criativas: reconhecer e difundir o potencial inovador e criativo da escola do século XXI.

\section{ORIGEM DA REDE INTERNACIONAL DE ESCOLAS CRIATIVAS (RIEC)}

O IV Fórum sobre Inovação e Criatividade organizado pelo grupo GIAD em Barcelona (junho, 2012), dedicado a Adversidade e Escolas Criativas, pode ser considerado como o germe da semente que havia enraizado no Brasil. Na realidade, já havia uma pessoa no estado de Goiás que vinha realizando sua tese de doutorado sobre as escolas criativas.

Podemos considerar este Fórum como o primeiro broto do movimento de Escolas Criativas que enraíza no subsolo do pensamento complexo, da ecoformação e do olhar transdisciplinar tendo como antecedente o expressado anteriormente. Tal qual reconhecida na Ata de Constituição (28 de março de 2012), "Saturnino de la Torre propõe a criação da Rede 
Internacional de Escolas Criativas (RIEC). Esta proposta tem seus antecedentes em uma linha de trabalho e pesquisa em torno da Rede de Ecologia de Saberes, Rede de Formação Universitária Transdisciplinar (REDFUT) e a Rede de Escolas Criativas iniciada em Barcelona no ano de 2007 e com experiências pioneiras na cidade de Orleans (Brasil)". Atualmente está sediada na Universidade de Barcelona, entretanto, em cada país existem núcleos de referência para aqueles grupos que a estimulam e a promovem ou estabelecem adesões institucionais. Está aberta a novas pessoas, grupos e instituições comprometidas com uma visão de educação e escola baseada no desenvolvimento humano, sem limitações de crenças, línguas, gênero, nem país.

A Rede, como expressão do Movimento de Escolas Criativas, apresenta três objetivos principais: 1) Criar uma consciência coletiva de mudança; 2) Gerar ações transformadoras; 3) Promover ações investigadoras e polinizadoras.

Em primeiro lugar, busca criar uma Consciência Coletiva de mudança na educação a partir dos centros pioneiros, inovadores e criativos, para promover uma educação transformadora baseada em valores, potenciais humanos e habilidades para vida. Construir as bases para futuras reformas desde o diálogo entre o novo saber pedagógico inter e transdisciplinar, a experiência docente e a gestão administrativa.

Em segundo lugar, pretende resgatar, reconhecer e difundir (polinizar) o potencial criativo de escolas e instituições educativas mais evoluídas, com trajetória inovadora, que possam servir de referência a outras escolas e ao poder público para a realização de reformas e melhorias no sistema educativo.

Em terceiro lugar, promover a pesquisa e a criação de recursos e instrumentos padronizados que permitam avaliar e reconhecer as instituições que possam servir de referência para as demais, em algum aspecto. Saber mais sobre os processos de transformação das instituições, suas dificuldades e forma de superá-las. Levar em conta a realidade, a insatisfação e os problemas como oportunidade de formação e mudança.

Estes três objetivos ou propósitos são especificados em objetivos mais acessíveis em curto prazo, como:

- Contribuir para que estas escolas ou instituições sintam-se parte de uma Comunidade mais ampla em que possam trocar experiências, dificuldades e conquistas.

- Promover a formação docente mediante seminários, cursos, encontros para que realmente se consiga uma mudança efetiva e generalizada dos modelos tradicionais de ensino.

- Estimular a pesquisa e criação de instrumentos que permitam avaliar e identificar aquelas escolas mais desenvolvidas e com capacidade de transformação.

- Realizar encontros locais, nacionais e internacionais para reunir e compartilhar experiências, progressos, dificuldades e conquistas em uma educação transformadora.

- Atribuir Diplomas e Certificados de reconhecimento criativo a pessoas, a instituições e a entidades que sejam merecedores de tal distinção.

- Ajudar a transformar os problemas educacionais e a insatisfação docente em oportunidade de formação e mudança, mediante pesquisa e formação.

Para atingir estes objetivos algumas estratégias são apresentadas, tais como:

- Constituir um Grupo de referência, de acolhida, de informação e de divulgação das experiências, vinculado ao grupo GIAD da Universidade de Barcelona. 
- Estabelecer canais de comunicação com todos os participantes da Rede, através da página da web, blog e boletins informativos.

- Realizar de reuniões, seminários e encontros a nível local, nacional e internacional.

- Participar de chamadas públicas com projetos de pesquisa.

- Criar, comparar e validar um instrumento para avaliar o desenvolvimento criativo de instituições educacionais (VADECRIE).

- Prestar assessoramento nos centros educacionais com desejo de mudança.

- Publicar e difundir experiências das instituições e escolares inovadoras e criativas.

- Incentivar o intercâmbio de estudantes e professores entre Centros de formação e pesquisa.

- Realizar concursos que promovam o reconhecimento de instituições criativas.

- Aprofundar as bases conceituais das organizações e Escolas Criativas.

A pergunta necessária é: O que entendemos por Escolas Criativas? Se vamos trabalhar com este conceito, devemos partir de uma definição que permita o diálogo, o intercâmbio e o avanço a partir de experiências e reflexões. Tomamos como ponto de partida o exposto na Ata de Constituição da RIEC (Espanha, 2012): "entendemos as escolas criativas como aquelas instituições educativas que vão além do ponto de partida (transcendem), que dão mais do que têm e vão além do que se espera (recriam), que reconhecem o melhor de seus alunos e professores (valorizam), que crescem por dentro e por fora buscando por tudo, a qualidade e a melhora (transformam). Em outras palavras, esses centros que desenvolvem os potenciais criativos dos estudantes, os valores humanos, os sociais, os de convivência, os de liberdade e criatividade, as habilidades para a vida, a iniciativa e empreendedorismo, dando importância ao desenvolvimento humano e ambiental sustentável e tentando sempre compatibilizar conhecimento com reconhecimento. Compartilham um olhar transdisciplinar e ecoformador. Resumindo, instituições vivas que transcendem, recriam, valorizam e transformam. Estes são os quatro pontos cardiais que orientam as instituições criativas.

\section{AS RAÍZES DE UMA PRÁTICA EDUCATIVA CRIATIVA}

Os fundamentos teóricos das disciplinas costumam causar uma má impressão entre os estudantes, que não percebem a utilidade dos conceitos abstratos. As explicações teóricas em geral cansam o público, mas estes estão predispostos a ouvir as experiências, as histórias, os exemplos vivos. Nos atrai mais a beleza da forma ou o sabor dos frutos do que o imbricado tecido da raiz. No entanto, sem eles não teríamos ramos, folhas e frutos. É a parte oculta, invisível aos sentidos, mas que alimenta e sustenta a árvore. Seriam, salvo as diferenças de analogia, como uma emaranhada e complexa rede neural que permite aflorar em forma de emoções, de pensamentos, ideias criativas ou respostas vitais.

As raízes têm uma tripla função: buscar e transformar os nutrientes para adequá-los às características das plantas, absorvê-los e levá-los para o topo mantendo a árvore firme sob condições adversas. Os princípios de um projeto, tendência ou movimento precisam de fundamentos teóricos que permitam o crescimento e desenvolvimento para dar frutos de qualidade.

Vendo dessa forma, se torna fascinante e estimulante investigar o subsolo das práticas educativas. Por que atuamos de uma forma e não outra? Por que pedimos aos estudantes um tipo de exercício e não outro? Por que avaliamos suas aprendizagens de uma maneira e não de outra?

ISSN 1982-4866. Revista Dynamis. FURB, Blumenau, v. 21, n. 1, p. 15-30, 2015 
Por trás dessas manifestações externas existem visões que as justificam. Para isso servem os fundamentos, para buscar alimentos saudáveis, adaptá-los aos sujeitos, fazê-los chegar à mente através do currículo ou espaço de formação e, sustentar um modelo consistente com a visão que temos.

A RIEC e o movimento das Escolas Criativas conduzem suas ideias sustentadas por: a) A escola como organização viva que aprende e se transforma; 2) A criatividade como consciência e valor com energia transformadora; 3) Os valores e o desenvolvimento humano como referência, frente ao discurso do desenvolvimento acadêmico tão ampliado; 4) O pensamento complexo, transdisciplinaridade e ecologia dos saberes, superando assim a fragmentação do conhecimento. O decálogo sobre Trasdisciplinariedade e Ecoformação sintetiza grande parte desses fundamentos.

A RIEC pretende aproximar três instituições e três olhares sobre a educação: A Universidade, com seu saber rigoroso e sistematizado, a Escola com seu saber prático e empírico, o Poder Público com seu saber pragmático, gestão de potenciais humanos e recursos para estimular e reconhecer os esforços inovadores. No ensino busca-se superar a fragmentação dos conteúdos das disciplinas por propostas mais integradoras em forma de projetos, oficinas, espaços ou locais de trabalho, estratégias criativas. A unidade da mudança inovadora não é a sala de aula, senão o centro, a instituição ou a escola e, em alguns casos, a região.

A Ecologia dos saberes, de que trata Moraes (2008), proporciona uma sustentação teórica aos princípios da RIEC. A ideia de uma educação transformadora, aspiração da Rede, está também presente em vários escritos de Moraes e Almeida (2012) como Os sete saberes necessários a uma educação transformadora e do grupo GIAD da Universidade de Barcelona.

Nosso pensamento está, de certo modo, sequiestrado por um paradigma que restringe e limita a realidade tangível, mensurável, comparável. A realidade é, contudo muito mais ampla, assim como a verdade sobre as coisas. A ecologia dos saberes, como a ecologia da antropologia, nos permite conhecer melhor a realidade e os contextos em que atuamos, conectando o mundo das ideias ao emocional, ao experiencial e artístico, ao cultural, ao sociopolítico, econômico e filosófico. Porque todos os olhares escondem saberes sobre o ser humano que pretendemos formar. Mas não só a nível individual, assim como humanidade. Cada ser humano é como uma célula do grande corpo da humanidade. Todos formam o "cérebro global" de que nos fala Laszlo (2009).

\section{RIEC FURB EM AÇÃO: POSSIBILIDADES E AVANÇOS}

Em 20 de julho/2012, a Universidade Regional de Blumenau-FURB firmou Acordo de Adesão com a Red Internacional de Escuelas Creativas- RIEC. Desta forma, a FURB integra a RIEC- Construyendo la escuela del siglo XXI, com sede na Universidade de Barcelona. A RIEC está fundamentada na pesquisa colaborativa entre os membros e na formação transdisciplinar e ecoformadora, para uma formação de qualidade, progressiva e sustentável, tanto no âmbito científico como humano.

O Programa de Extensão REDE DE ESCOLAS CRIATIVAS da FURB (RIEC FURB) baseia-se na interdisciplinaridade, transdisciplinaridade, complexidade e na ecoformação como princípios investigativos e formativos.O Programa da FURB faz parte da Red Internacional de Escuelas Creativas (RIEC), com atuação na Argentina, Bolívia, Brasil, Chile, Colômbia, Espanha, México, Peru e Portugal que, entre outras metas, pretende potencializar o estabelecimento de parceria investigativa em rede e em cooperação Internacional, fundamentais para o desenvolvimento da pesquisa na FURB e no Brasil. 
A proposta pedagógica do Programa objetiva auxiliar profissionais da educação em busca de práticas educativas que contemplem os avanços das ciências e das tecnologias, bem como as demandas pessoais, sociais e ambientais deste início de século. Isto fica claro no depoimento de uma das participantes do grupo de estudos da RIEC na FURB, que afirma: “... pude conhecer pessoas que tem um olhar inovador sobre a ideia de que tipo de cidadão queremos formar; o que os jovens e as crianças do século XXI esperam da escola; para onde caminha o mundo numa visão holística; transdisciplinar; como países europeus pensam e caminham..." (Gestora da Rede Estadual de Ensino).

A RIEC FURB promove encontros de formação de professores e disseminação de experiências de escolas criativas de nossa região com o objetivo de ampliar as ações de práticas educativas inovadoras norteadas pelos princípios de ecoformação e transdisciplinaridade. Outro depoimento sinaliza que "os encontros me proporcionaram uma reflexão sobre a minha prática docente. Vislumbrei uma oportunidade de validar o desejo de provocar mais participação nas aulas... A participação em encontros nos quais o profissional da educação "o professor" é tão valorizado, também, nos estimula a continuar nessa caminhada." (Professora da FURB)

Além das ações que já acontecem, no sentido de capacitar e auxiliar os professores e acadêmicos da graduação e da pós-graduação e também visando às novas demandas educacionais que se apresentam para nossa instituição, há a preocupação permanente com a qualidade desta formação, bem como com a educação continuada e qualificação de professores. Os resultados desta preocupação com a qualificação docente são evidenciados na fala de um dos professores que participa dos encontros: "Em uma IES pautada historicamente pelo cartesianismo e por aulas assentadas em um pensamento linear, participar de um grupo de pensamento divergente e complexo, é terapêutico e renova as energias, além de fortalecer os nós em forma de rede, caminhando para a transdisciplinaridade. ” (professor da FURB).

Neste sentido, estes projetos têm beneficiado professores do ensino fundamental, médio e superior; estudantes e comunidade, uma vez que as ações propostas visam incluir uma prática educativa que esteja atenta à qualidade de vida e as relações com o meio ambiente, comprometidas com as questões relacionadas às necessidades das comunidades que cercam as escolas.

Além disso, o Programa tem aprofundado as questões reflexivas acerca da ecoformação e transdisciplinaridade, na busca de formação inicial e continuada de professores, enfocando questões conceituais e metodológicas. Do mesmo modo, pesquisa e identifica iniciativas, ações e projetos criativos e inovadores em escolas da rede pública de ensino de Blumenau.

Após o Acordo de Adesão com a Red Internacional de Escuelas Creativas- RED RIEC, os três projetos reforçam suas ações comprometidas com a Ecoformação, Criatividade e Transdisciplinaridade. Os Programas de extensão da FURB: Arte na Escola, Ciências para o século XXI e RIEC, a partir de 2012, passaram a realizar na FURB ações em parceria. Os estudos e reflexões dos Programas tem oferecido a possibilidade de repensar e reorganizar a formação de professores na comunidade e, além disso, reconhecer, valorizar e tornar a escola um lócus de reflexão e ação para a promoção de práticas educativas inovadoras e criativas. Isto fica claro em alguns depoimentos, na sequência, de professores que participam de nossos encontros de formação da RIEC na FURB: “... percebo que a Rede tem como um dos objetivos valorizar a contribuição das experiências de cada profissional. A cada encontro, o aprendizado é expandido." (Profa. da Rede Estadual de Ensino). 
A partir da presença da RIEC na FURB, está se abrindo um leque de possibilidades para pesquisas em Formação de Professores: Ecoformação, Criatividade e Transdisciplinaridade vinculadas tanto ao Mestrado Profissional de Ensino de Ciências Naturais e Matemática (PPGECIM/FURB), como aos cursos de Licenciatura da FURB, especialmente em pesquisas para Trabalhos de Conclusão de Curso (TCC) e dissertações de mestrado.

Uma dessas produções foi a realização do TCC do Curso de Pedagogia, da FURB, de autoria da aluna Daiana Cardoso e sob a orientação da Profa. Vera Lúcia de Souza e Silva, como pesquisa qualitativa e quantitativa utilizando o VADECRIE (Instrumento da REDE RIEC) numa escola da região, intitulada: Investigação sobre criatividade em uma escola da rede pública de Blumenau-SC. O trabalho foi socializado com a escola pesquisada (E.B.M. Visconde de Taunay, de Blumenau-SC) e a certificação como Escola Criativa pela REDE RIEC, das mãos do seu mentor Prof. Saturnino de la Torre, aconteceu na FURB no dia 13/maio/2013, com a presença de autoridades, tais como: João Natel Pollonio Machado (Reitor FURB), Vera L. de Souza e Silva (RIEC FURB), Saturnino de la Torre(Universidade de Barcelona-RIEC), Sinclair Ferreira (Diretora da EBM Visconde de Taunay) e Napoleão Bernardes( Prefeito de Blumenau), conforme Figura 1.

Figura 1-Diplomação Escola Criativa- maio/2013-FURB.

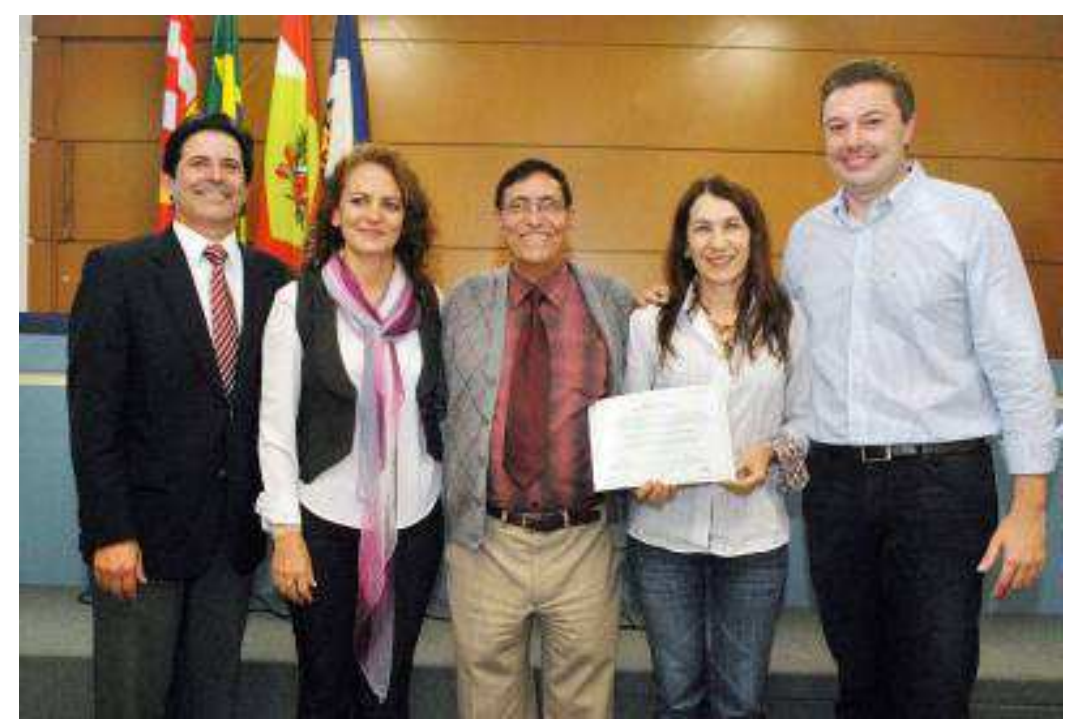

Fonte: Arquivo de Rogério Pires

Além disso, desenvolvemos nesta escola o estágio curricular supervisionado com acadêmicos do curso de graduação em Ciências Biológicas, na disciplina de Estágio na Licenciatura (108h/a), com o enfoque da docência na ecoformação e transdisciplinaridade. Esta parceria entre Escola e Universidade permite ampliar as possibilidades de formação inicial dos futuros professores a partir de uma vivência reflexiva numa escola campo que norteia suas práticas docentes nos pressupostos epistemológicos norteadores da ação da RIEC. Trata-se de um trabalho que visa contribuir na formação inicial de futuros professores de Ciências e Biologia com um olhar para uma escola transformadora e que desenvolva experiências criativas e inovadoras. Dentre várias experiências de estágio realizadas na escola, destacamos uma mais significativa, realizada em 2014 com 26 estagiários, pois partiu do tema sugerido pela escola para contribuir com a proposta de sustentabilidade prevista no projeto político pedagógico, a partir do tema: "Chicletes: sustentabilidade do corpo e do meio 
ambiente”. O grupo de acadêmicos desenvolveu o estágio articulando teoria à prática, a partir dos fundamentos da ecoformação e criatividade. Além disso, a experiência foi orientada para que os estágios se constituíssem espaços de concretizar observações sobre as realidades escolares, de refletir as concepções de aprender e ensinar; de encontro com estudantes e professores no cotidiano escolar, de planejar, de iniciar processo de docência e de ampliar seu universo conceitual sobre o espaço Escola.

A gestão e grupo de professores da escola, quando questionados sobre as contribuições que a RIEC vem trazendo para a Escola Visconde de Taunay, apontam para " a vinda da Universidade para dentro da escola, a formação para professores e equipe gestora, divulgação dos trabalhos escolares, desacomodação de alguns profissionais e a concepção de escola criativa influenciando a prática dos professores." (Gestão e docentes da EBM Visconde de Taunay). Um dos impactos percebidos com a certificação da escola pela RIEC foi a necessidade de formação continuada na direção de aprofundar os saberes docentes nos pressupostos de ecoformação, criatividade e transdisciplinaridade. Devido a isso, atualmente 04 professores da escola estão cursando o Mestrado Profissional em Ensino de Ciências Naturais e Matemática da FURB, e o objeto de estudo de suas dissertações será a própria escola com seus processos de gestão, currículo e práticas docentes inovadoras e criativas.

Isto nos permite refletir sobre o papel atuante da RIEC na comunidade, que a partir de pesquisas e de formação, pode colaborar para ampliar as possibilidades de atuação e de aproximação da Universidade na comunidade; oportunizar reconhecimento e valorização de experiências criativas e inovadoras em instituições de ensino.

Estes resultados são congruentes com alguns dos objetivos da RIEC, que apontam para: "Criar uma consciência e cultura de mudança entre gestores escolares para que promovam uma formação de professores com uma visão mais aberta e flexível sobre sua função formadora; Contribuir para que estas escolas e instituições sintam-se parte de uma comunidade mais ampla e que possam compartilhar suas experiências, desafios e conquistas; e Promover a formação dos professores por meio de seminários, cursos, reuniões para que realmente se alcance uma mudança eficaz e generalizada dos modelos educacionais tradicionais" (Acta de Constituición RIEC, Barcelona- 2012, p. 02).

Outras pesquisas sob o enfoque da Ecoformação e da Transdisciplinaridade para a educação básica estão em andamento, e resultarão em quatro dissertações de mestrado do PPGECIM (Programa de pós-graduação de Ensino de Ciências e Matemática da FURB), no período de 2013 e 2014. Também estamos realizando três pesquisas de iniciação científica, sobre "Escolas criativas: investigação e avaliação de processos educativos". Estas pesquisas tem como objetivo geral investigar o grau de desenvolvimento criativo de Escolas da região do Médio Vale do Itajaí a partir do instrumento de avaliação da RIEC (VADECRIE). A partir destes resultados, as escolas pesquisadas serão convidadas a ser membro da RIEC, em que poderão socializar e difundir suas práticas educativas e intercambiar experiências, dificuldades e avanços em seus processos de ensinar e aprender.

Ações conjuntas estão acontecendo para publicação de livros e capítulos de livros, tais como a obra "Inovando na sala de aula: instituições transformadoras", organizado por Saturnino de la Torre, Maria Antónia Pujol e Vera Lúcia de S. e Silva (Nova Letra, 2013) com contribuições sobre escolas criativas a partir da abordagem da transdisciplinaridade e ecoformação. Em 2014 publicamos a obra "Novos Talentos: processos educativos em ecoformação", organizada por Edson Schroeder e Vera L. de S. e Silva (Nova Letra), resultado da experiência acumulada de pesquisadores, professores universitários e da educação básica, e estudantes de graduação e pós-graduação da FURB, profundamente engajados e envolvidos em torno de questões essenciais relativas ao desenvolvimento do 
pensamento criativo, formação humana e ecoformação na educação. Esta obra terá mais dois volumes (no prelo), a serem publicados em dez/2015 com os títulos: "Novos Talentos: processos educativos em Clubes de Ciências" (organizado por Daniela Tomio, Edson Schroeder e Vera L. de S. e Silva) e "Novos Talentos: processos educativos com Projetos Criativos Ecoformadores" (de Schirley Pasquali e Vera L. de S. e Silva). Estas obras pretendem divulgar os resultados de pesquisas e experiências de práticas docentes criativas e ecoformadoras na educação básica e no ensino superior, a partir dos referenciais teóricometodológicos da RIEC.

Outra participação foi com um capítulo na obra "Criatividade e inovação no ensino superior: experiências de ensino, pesquisa e extensão latino-americanas e europeias em debate", organizada por Marlene Zwierewicz (Editora da UFPB, 2013). Além disso, contribuímos com um capítulo no livro "Resiliência, criatividade e inovação: potencialidades transdisciplinares na educação" - organizado por Marilza Suanno, Maria Antonia Pujól e Maria Glória Dittrich (Editora da UEG, 2013). Em 2015 participamos com um capítulo na obra "Projetos Criativos na Prática Pedagógica: cantar e encantar a aprendizagem" organizada por Maria J. de Pinho, Marilza V.R. Suanno e João Henrique Suanno (Editora Espaço Acadêmico, 2015).

Publicamos na Revista Atos de Pesquisa em Educação, volume 4, número 3 de 2012, vinculada ao Programa de Pós-Graduação em Educação (PPGE/FURB), o artigo intitulado: "Clubes de Ciências como espaço de alfabetização científica e ecoformação", com Edson Schroeder e Celso Menezes. Este artigo apresenta reflexões acerca do papel dos Clubes de Ciências como possibilidade para o desenvolvimento de atitudes e senso crítico, uma vez que pode propiciar condições adequadas para o estudante debater, discutir e refletir sobre aspectos éticos e morais na utilização de conhecimentos para o entendimento de processos que envolvem os conhecimentos científicos e as tecnologias. A transformação da prática educativa em convergência com as necessidades de sustentabilidade planetária e o estímulo a relações de convivência solidárias tendem a ser aspectos fundamentais dos debates das políticas públicas de qualquer sistema e/ou instituição educativa preocupada em qualificar a vida no planeta. Apresentamos, a partir de um portfólio de atividades destinadas aos Clubes de Ciências, a integração de duas propostas denominadas Cineciência e o boletim informativo objetivando conduzir os estudantes participantes de um Clube na articulação entre pensamento e linguagem, a partir da inserção e aprofundamento sobre temas diversos, embasados nas dimensões conceituais, procedimentais e atitudinais, tendo-se como ponto de partida a ciência e seus conhecimentos para a sustentabilidade. Outras publicações com resultados de pesquisas realizadas a respeito das ações da RIEC FURB estão disponíveis em outros periódicos, tais como: SILVA, V. L. S. ; SOUZA, R. . Rede Internacional de Escolas Criativas: contribuições na formação de professores. Revista Electrónica de Investigación y Docencia, v. 13, p. 117-134, 2015. Temos também o artigo de autoria de CARDOSO, D. ; SILVA, V. L. S. . Investigação sobre criatividade em uma escola da rede pública de Blumenau - SC. Revista Electrónica de Investigación y Docencia, v. 11, p. 107-122, 2014. E o artigo de SILVA, V. L. S. . Contribuições dos princípios da complexidade no processo de aprender biologia na formação inicial de professores. Enseñanza de las Ciencias, v. 01, p. 3287-3291, 2013. Outra publicação a respeito da prática docente em: SILVA, V. L. S. . A Transdisciplinaridade na formação inicial de Professores. Dynamis (FURB. Online), v. 19, p. 19-32, 2013.

Além disso, participamos em eventos internacionais para publicação dos resultados das ações da RIEC FURB em países como a Espanha, no Canadá e Perú, no período de 2012 a 2014. Entre as publicações podemos destacar a pesquisa Institutional Program Creative 
Schools Network and Teacher Training apresentada no $20^{\circ}$.Collóque International en Éducation, na Universidade de Montreal-Canadá (Maio/2013). No $9^{\circ}$. Congresso Internacional sobre Investigação em Didática de las Ciências, na Universidade de GironaEspanha (setembro/2013) foram apresentados os seguintes trabalhos: "Contribuições dos princípios da complexidade no processo de aprender biologia na formação inicial de professores" e "Interdisciplinaridade no ensino de ciências: uma experiência pedagógica inovadora". Os objetivos das pesquisas citadas anteriormente foram respectivamente: investigar as contribuições dos princípios da complexidade para o ensino de biologia humana na formação inicial de pedagogos; e investigar as contribuições da proposta metodológica baseada na interdisciplinaridade e na contextualização dos conteúdos no processo de alfabetização científica de estudantes de ensino médio.

Outra forma de ampliação de ações dos membros da RIEC FURB concretizou-se a partir de dois Intercâmbios Acadêmicos (Figuras 2 a 4) realizados por um grupo de sete acadêmicos e um docente da pós-graduação da FURB (PPGE e PPGECIM- Mestrado em Educação e Mestrado em Ensino de Ciências e Matemática), na Espanha em 2013 e 2014. Parte destes intercâmbios aconteceu como visita de estudos ao Grupo GIAD- da Universidade de Barcelona (UB) e RIEC-Rede Internacional de Escolas Criativas (convênio UB e FURB), representada pela profa. Dra. Vera Lúcia de Souza e Silva e pela profa. Dra. Vera Simão (RIEC FURB). Estas viagens tiverem apoio financeiro do CNPq e da Fundação Fritz MullerBlumenau-SC. O intercâmbio enfocou também a visita orientada a escolas de educação básica de Barcelona, para aprofundar o estudo do sistema educacional espanhol e verificar na prática os resultados de parcerias estabelecidas pela RIEC com escolas da Cataluña. Estas viagens contribuíram ainda para ampliar o repertório científico-cultural e social do grupo de pesquisadores da RIEC FURB, resultado de uma viagem internacional.

Figura 2- Reunião RIEC- Universidade Barcelona - set/2013

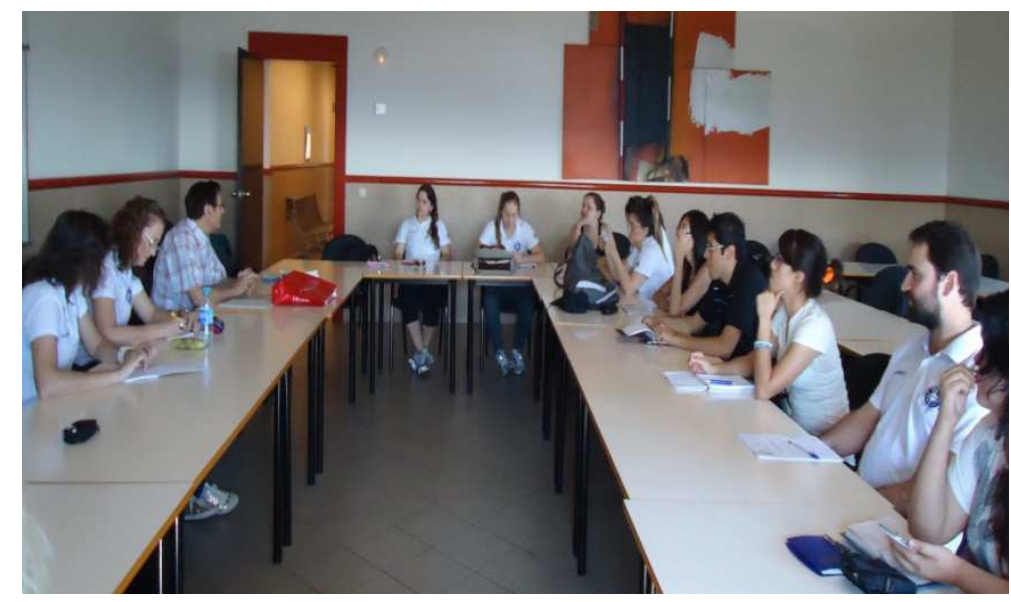

Fonte: arquivo RIEC

Figura 3- Visita a escolas Criativas (Escola CanFabra)- Barcelona set/2013 


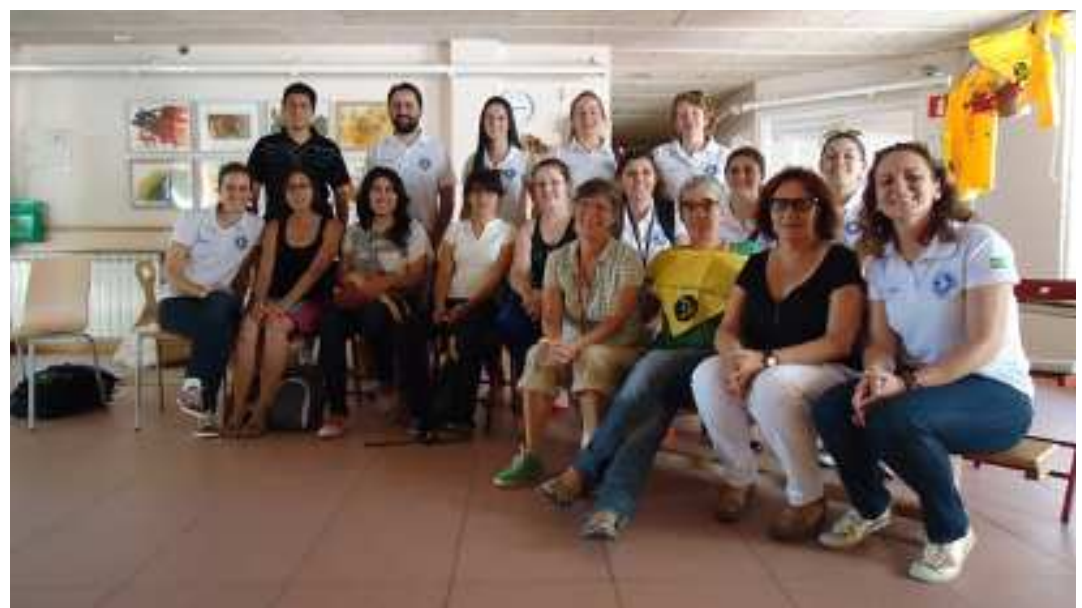

Fonte: arquivo RIEC

Figura 4- Visita do Grupo FURB à RIEC de Barcelona- julho/2014

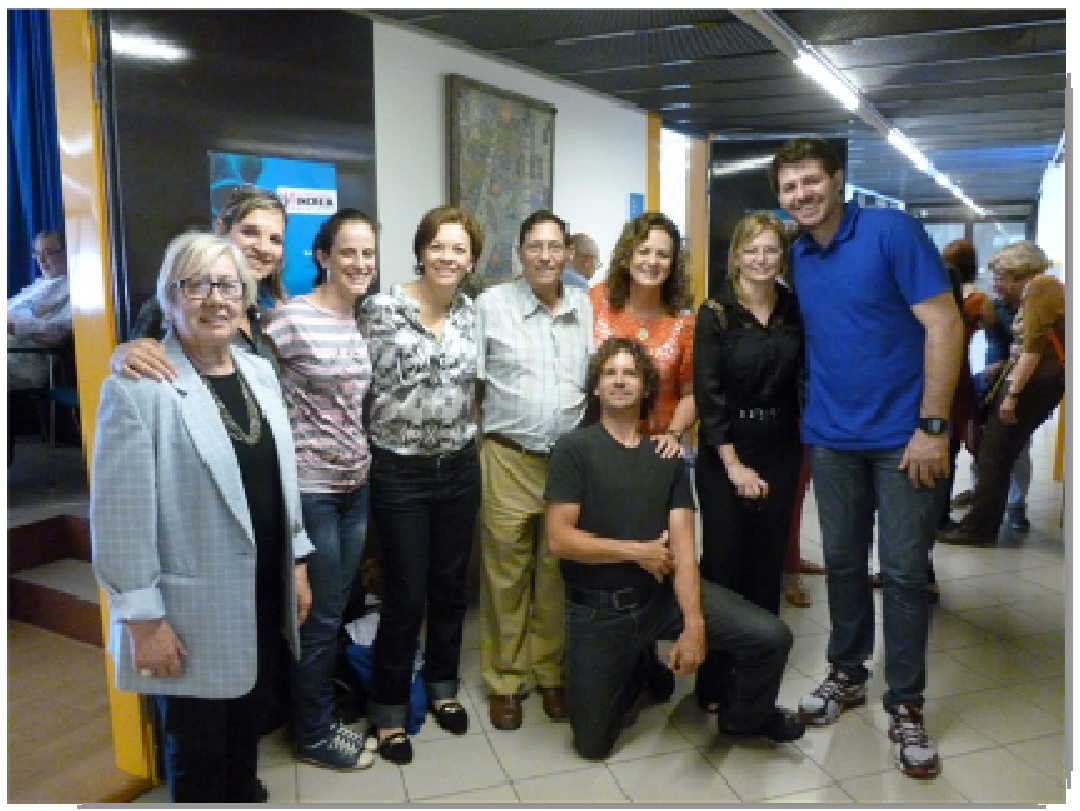

Fonte: arquivo RIEC

Os objetivos destas visitas de estudos visaram socializar conhecimentos e projetos de pesquisa e extensão efetuados pelo Grupo GIAD, grupo RIEC e pelo grupo do PPGECIM (FURB), bem como conhecer as propostas educativas de escolas criativas da região de Barcelona, investigadas pelo grupo GIAD. O grupo foi recebido por Saturnino de la Torre, Maria Antónia Pujól e Núria Lorenzo, professores da Universidade de Barcelona. Como parte do convênio entre FURB e Universidad de Barcelona (UB), em 2013, 2014 e 2015 tivemos a presença na FURB do professor emérito da UB, Saturnino de la Torre, mentor da RIEC. Durante sua permanencia na FURB o profesor visitante cumpriu uma série de atuações em diversos cursos de graduação e pós-graduação da FURB desenvolvendo ações de ensino, pesquisa e extensão na temática da Criatividade, Ecoformação e Transdiciplinaridade. 
Estas experiências de intercâmbio foram socializadas em eventos científicos e reuniões de estudos da RIEC FURB, com os objetivos de compartilhar experiências e ações da RIEC e discutir possibilidades de práticas educativas inovadoras na educação básica a partir da experiência de escolas criativas do Brasil e da Espanha.

Um grupo de cinco professores da FURB, entre eles dois da RIEC, participou do Edital da CAPES do Programa Novos Talentos 2013, com o projeto "Ecoformação e Literacia Informacional para a Educação Científica" com aprovação em segundo lugar no Brasil, dentre as 86 universidades classificadas. O objeto deste Edital é apoiar propostas para realização de atividades extracurriculares para professores e alunos da educação básica, visando ao aprimoramento e à atualização do público-alvo e a melhoria do ensino de ciências nas escolas públicas do país. O sub-projeto "Ciclo de formação para Ecoformação e Biodiversidade", elaborado por integrantes da RIEC FURB, está recebendo financiamento da CAPES para um ciclo de formação de dois anos para 25 professores e 145 alunos das escolas parceiras de Blumenau, com o intuito de qualificar a prática docente nos pressupostos teóricometodológicos sobre a temática ecoformação e biodiversidade e disseminar nas unidades escolares esse ciclo de qualificação.Trata-se de mais uma ação de formação de professores da escola pública, baseada em pressupostos de ecoformação e transdisciplinaridade que vão colaborar para a implementação de propostas educativas inovadoras e criativas.

Os impactos desta formação estão se manifestando na forma de 25 projetos de ecoformação que acontecem nas escolas em que os professores participantes do Ciclo atuam, como forma de disseminar a proposta de Projetos Criativos Ecoformadores na educação básica. Além disso, o ciclo foi objeto de estudo de duas dissertações de mestrado do PPGECIM-FURB, das alunas Fabiana Fachini (Ecoformação de professores da educação básica no Programa Novos Talentos da CAPES, 2014) e Schirley Pasquali (Projetos Criativos Ecoformadores: uma proposta de ensino de ciências para o estudo da alimentação saudável, 2015) voltadas ao tema de formação de professores e criatividade na prática docente. Foram publicadas várias pesquisas de iniciação científica e resultados de trabalhos de extensão realizados a partir dos projetos nas escolas na forma de três livros do Novos Talentos (sobre Ecoformação em escolas, em Clubes de Ciências e na forma de Projetos Criativos ecoformadores) anunciados anteriormente neste texto.

Além disso, o Programa tem constatado que existem várias práticas educativas implementadas pelos docentes de escolas de educação básica, que podem contribuir como um banco de dados rico em experiências e vivências que a comunidade escolar vem produzindo e amadurecendo na direção da ecoformação. Estes podem se revelar como um potencial de ações que podem ser reconhecidas e avaliadas por pesquisas pela Universidade para posteriormente serem utilizadas e citadas na formação inicial e continuada de professores. Para isso desenvolvemos duas pesquisas de iniciação científica financiadas pelo CNPq (2014 e 2015) intituladas "Escola Sustentável: contribuições da ecoformação para uma proposta inovadora na educação básica", cujo objetivo geral foi avaliar o desenvolvimento do processo de ecoformação de instituições de ensino de educação básica da região de Blumenau-SC. Os resultados e discussões destas pesquisas estão contribuindo significativamente para ampliação dos referenciais teórico-práticos dos cursos de pedagogia e ciências biológicas da FURB, assim como ao Programa de Pós-Graduação em Ensino de Ciências Naturais e Matemática (PPGECIM) e do Programa Institucional RIEC FURB.

Todas as ações e os trabalhos anunciados anteriormente, entre eles: formação inicial e continuada de professores, projetos e programas de pesquisa e extensão, certificação de escola criativa, livros, capítulos de livros, artigos e comunicações em eventos são implicações de atuações dos participantes da RIEC FURB (alunos de graduação e pós-graduação, professores

ISSN 1982-4866. Revista Dynamis. FURB, Blumenau, v. 21, n. 1, p. 15-30, 2015 
do ensino superior e educação básica) e estão contribuindo para a divulgação das concepções teórico-metodológicas da RIEC. Estes resultados selam o acordo que assumimos como membros fundadores no ato de criação da Rede Internacional de Escolas Criativas, de nos "comprometer a favor de uma escola criativa e transformadora, deixando constante o compromisso de participar, impulsionar e difundir as experiências de escolas criativas, assim como sua valorização e reconhecimento" (Acta de Constituición RIEC, Barcelona, 2012, p. $01)$.

\section{OUTROS NÚCLEOS E CENTROS DE ESCOLAS CRIATIVAS}

Por trás das instituições e grupos que impulsionam um projeto, existem pessoas motivadas e comprometidas. No estado de Goiás (GO) a investigação coordenada por J. H. Suanno propicia conhecimentos e, melhora o instrumento que permite avaliar o desenvolvimento criativo. Existe uma adesão à RIEC pelas Universidades Federal e Estadual, tendo como Coordenadores Marilza e João Suanno. Um trabalho fundamentado no pensamento complexo e no olhar transdisciplinar, aplica os dez parâmetros de Escolas Criativas ao Colégio Logosófico, com resultados que os tornam dignos de reconhecimento.

No estado do Ceará nossa atenção se concentra na Escola Vila de Fortaleza, dirigida por Fátima Limaverde e representada por Patricia Limaverde. O grupo de professores tem uma formação transdisciplinar trabalhando com projetos que vinculam a vida, a sociedade e a natureza. Como anunciado pela gestão da escola:

\footnotetext{
se você fizer uma visita à Escola VILA você verá muitos alunos fora de sala, com seus professores em atividades na horta, na farmácia viva, no jardim, no pomar, nos animais, na carpintaria, nas aulas de artes, de música, de corpo, etc. Irá presenciar alunos e professores em grupos, discutindo e implementando seus projetos. (LIMAVERDE, 2013)
}

Outro centro que trabalha com uma visão criativa é a Escola Tarsila do Amaral (São Paulo) que atende a crianças de meses até os cinco anos de idade. A escola toda é um lugar de aprendizagem, onde as famílias participam e a expressão artística forma parte do entorno visual.

No Peru encontramos outro núcleo de estudo e de prática transdisciplinar na Universidade Ricardo Palma, graças à ousadia e direção de T. Salinas e o entusiasmo da diretora do Colégio Brüning, Alicia Montenegro. Sua dedicação para transformar o centro em um referencial em criatividade e resiliência a levaram a organizar um Congresso de caráter internacional voltado à formação de professores.

O conceito de Escola criativa pode adotar múltiplas tendências e manifestações. Não é algo fechado e estático. Antes de tudo é um processo, um movimento que vai evoluindo em harmonia e com repercussão em outras instituições, grupos e coletivos. Por isso é importante considerar o marco teórico que enraíza este movimento que estamos descrevendo e, que estes contam com pessoas semeadoras e polinizadoras em vários países da América Latina.

\section{CONCLUSÕES}

Os resultados das ações da RIEC FURB, mesmo iniciais, apontam que estamos colaborando institucionalmente para a formação inicial e continuada de professores numa 
abordagem da ecoformação, criatividade e transdisciplinaridade. Isto, por sua vez pode contribuir para a implementação de práticas pedagógicas inovadoras e criativas, focadas na sustentabilidade, na sociedade do conhecimento.

Já é possível perceber que os fundamentos da REDE RIEC estão amadurecendo nos primeiros frutos. Professores que frequentam os encontros passaram a olhar mais seu interior, buscam aflorar sentimentos que pareciam esquecidos, mas que influenciavam suas práticas educativas. Trabalhar esses sentimentos, de modo a anular suas decepções, melhora e oportuniza encontros com alunos de maneira prazerosa ao estabelecer vínculos interativos, uma relação de compartilhamento de emoções, sucessos e derrotas. Nosso corpo passa a falar e os alunos passam a nos compreender. Esse novo processo de ensinar exige dos professores um desaprender, uma reaprendizagem, aprendizagem e complexibilização de um objeto. Não falaremos mais em ensino-aprendizagem puro descontextualizado, iremos articular as pesquisas científicas com os acontecimentos diários (González, 2006). Podemos mostrar que conteúdos ministrados não são lineares, e que podemos agregar o conhecimento de diversas áreas oportunizando ao aluno uma visão mais complexa do seu entorno.

As parcerias estabelecidas são fundamentais como alicerce de um novo olhar para a formação de professores. Nossas ações conjuntas têm beneficiado professores e acadêmicos da graduação e pós-graduação, bem como de professores da educação básica ao privilegiar as ações e práticas educativas direcionadas à qualidade de vida e às relações saudáveis com o meio ambiente, na busca por uma educação e em um mundo melhor para todos.

\section{REFERÊNCIAS}

ACTA DE CONSTITUICIÓN RIEC. UB: Barcelona, 2012. Disponível em http://www.escuelascreativas.com, acesso em 20 de dezembro de 2013.

BERNHEIM, C. T., CHAUÍ, M. S. Desafios da universidade na sociedade do conhecimento: cinco anos depois da conferência mundial sobre educação superior. Brasília: UNESCO, 2008.

BARBOSA, Ana Mae. A imagem no ensino da arte: anos oitenta e novos tempos. São Paulo: Perspectiva, 1999.

D’AMBROSIO, U. Transdisciplinaridade. São Paulo: Palas Athena, 2002.

LASZLO, Erving. El cambio cuántico. Barcelona: Kairós, 2009.

LIMAVERDE, P. Escola Vila: proposta pedagógica. In: ESCOLA VILA. Disponível em http://www.escolavila.com.br/proposta-pedagogica. Acesso em 20 de dezembro de 2013.

MARIOTTI, Humberto. As paixões do ego: Complexidade, política e solidariedade. São Paulo: Palas Athena, 2000.

MORAES, M. C.; Torre, S. de La. Sentipensar: fundamentos e estratégias para reencantar a educação. Petrópolis: Vozes, 2004.

MORAES, M. C.. Ecologia dos saberes: complexidade, transdisciplinaridade e educação. São Paulo: Antakarana/WHH, 2008. 
Moraes, M.C., \& ALMEIDA, M.A. Os sete saberes necessários a uma educação transformadora. Rio de Janeiro: Wak, 2012.

MORIN, E.. A cabeça bem feita: repensar a reforma, reformar o pensamento. Eloá Jacobina. Rio de Janeiro: Bertrand Brasil, 2000.

NÓVOA, A.. Os professores e a sua formação. Lisboa: Publicações Dom Quixote, 1995.

PILLAR, A. D. A educação do olhar no ensino da arte. In: BARBOSA, Ana Mae. (org.). Inquietações e mudanças no ensino da arte. São Paulo: Cotez, 2002.

SILVA, V.L.S. (2004). Educar para a conexão: uma visão transdisciplinar de educação para a saúde integral: Blumenau: Nova Letra, 2004.

- Estágio na formação de professores no ensino superior: uma vivência transdisciplinar. In: TORRE; PUJOL; SILVA (Org.). Inovando na sala de aula: instituições transformadoras. Blumenau: Nova Letra, 2013.

TORRE, Saturnino de la.. Transdisciplinaridade e ecoformação: um novo olhar sobre a educação. São Paulo: TRIOM, 2008.

. Uma escola para o século XXI: escolas criativas e resiliência na educação. Florianópolis: Insular, 2009.

Formação docente e pesquisa interdisciplinar: criar e inovar com outra consciência. Blumenau: Nova Letra, 2011.

Instituciones educativas creativas. Sevilla: Círculo Rojo, 2012.

Instrumento para avaliar o desenvolvimento criativo de instituições de ensino (VADECRIE). Barcelona: Círculo Rojo, 2012.

TORRE, S. De la; PUJOL, M.A. Educar con otra conciencia. Una mirada ecoformadora y creativa de la enseñanza. Barcelona: Davinci, 2009.

TORRE, S. De la; PUJOL, M.A.; MORAES, M.C. Documentos para el cambio. Hacia una educación transformadora. Sevilla: Círculo Rojo. Versión portuguesa en editora Wak, 2011.

TORRE, S. De la; ZWIEREWICZ, M.; FURLANETTO, E. Formação docente e pesquisa transdisciplinar. Blumenau: Nova Letra, 2010. 